J. Lake Sci. (湖泊科学), $2007,19(5): 544-551$

http:// www. jlakes. org. E-mail: jlakes@ niglas. ac.cn

(c) 2007 by Journal of Lake Sciences

\title{
太湖西南部河流流域的营养盐排放
}

许朋柱 ${ }^{1}$, 秦伯强 ${ }^{1}$, Horst Behrendt ${ }^{2}$, 章永鹏 ${ }^{1}$, 艾 敏 $^{1}$, 沈顺雨 ${ }^{3}$

( 1 : 中国科学院南京地理与湖泊研究所, 南京 210008)

$(2$ : 德国淡水生态与内陆渔业研究所, 柏林 D - 12587)

( 3 : 浙江省湖州市环境科学研究所, 湖州 313000 )

摘 要: 以 MONERIS 河流系统模型为基础, 建立了由农业土地营养盐平衡模型、流域营养盐排放模型及河道营养盐滞留 模型 3 个模型组成的模型系统. 该系统被用来计算太湖西南部河流流域的营养盐排放量. 利用实测的河流系统的负荷数 据,对模型系统进行验证. 验证结果表明, N、P 计算负荷与实测负荷的偏差分别在 10\% 及 30\% 以内. 利用该系统,对 1992 -1996 年及 $1997-2001$ 年间的营养盐排放量进行计算. 计算结果表明, $1997-2001$ 年间的氮的年平均排放量为 $5646 \mathrm{t} /$ $\mathrm{a}$,该排放量比前 5 年的年均排放量减少 $827 \mathrm{t} / \mathrm{a}$. 从磷的排放量来看, $1997-2001$ 年间的年排放量为 $554 \mathrm{t} / \mathrm{a}$, 比前 5 年的均 值减少 $45 \mathrm{t} / \mathrm{a}$. 分析结果表明,与 $1992-1996$ 年相比, 1997-2001 年间的点源排放量及农业土地营养盐剩余量的减少是流 域营养盐排放量减少的主要原因.

关键词:太湖;营养盐;剩余量;排放量;负荷;GIS; MONERIS 模型

\section{Estimation of nutrient emissions into the river system of the southwestern Taihu Basin}

\section{XU Pengzhu ${ }^{1}$, QIN Boqiang ${ }^{1}$, HORST Behrendt ${ }^{2}$,ZHANG Yongpeng ${ }^{1}$, AI Min ${ }^{1} \&$ SHEN Shunyu ${ }^{3}$}

( 1 : Nanjing Institute of Geography and Limnology, Chinese Academy of Sciences, Nanjing 210008, P. R. China)

(2:Leibniz Institute of Freshwater Ecology and Inland Fisheries, Berlin D-12587, Germany)

(3: Huzhou Institute of Environmental Sciences, Huzhou 313000, P. R. China)

\begin{abstract}
According to MONERIS, three models were established to estimate the nutrient emissions into the river systems of the southwestern Taihu Basin,i. e, a nutrient balance model of the agricultural land, an emission model that was used for the estimation of nutrient emissions from catchments to river systems, and a riverine retention model that was used for the estimation of nutrient loads from emissions. The comparison of the calculated loads with the observed loads shows a deviation as low as $10 \%$ and $30 \%$ for nitrogen and phosphorus, respectively. It was estimated that the nitrogen input into the river system amounts to about $5645 \mathrm{t} / \mathrm{a}$ in the period $1997-2001$. These emissions have decreased since the former five years by about $827 \mathrm{t} / \mathrm{a}$. For phosphorus the emissions have reduced by $45 \mathrm{t} / \mathrm{a}$ and amount $554 \mathrm{t} / \mathrm{a}$ in the period 1997 - 2001. Analysis of the results show that the decrease of the nutrient emissions are mainly caused by the great reduction of nutrient surpluses from the agricultural land and the emissions from point sources.
\end{abstract}

Keywords: Taihu Basin; nutrients; surpluses; emissions; loads; GIS; MONERIS

流域河流系统是营养盐进入湖泊或海洋的输运通道. 从流域进入河流系统的营养盐排放量的多葟, 不 仅影响河流系统本身的营养状态, 而且导致湖泊或海洋的营养水平发生变化 ${ }^{[1-4]}$. 如何正确地计算和预测 流域营养盐进人河流系统的排放数量的变化,对于湖泊或海洋的富营养化防治,具有重大意义.

在流域营养盐排放量的研究中, 最原始也是最直接的方法是利用实测的流量及浓度数据进行推算 ${ }^{[4]}$, 其次是利用数学模型进行计算 ${ }^{[5]}$. 从模型分类来看, 既有简单的统计或相关模型, 也有复杂的模拟模型; 既

* 中国科学院知识创新工程项目 (KZCX1 - SW - 12) 及德国科学基金会( DAAD) 联合资助. $2005-12$ - 05 收稿;2006 $-12-26$ 收修改稿. 许朋柱,男,1965 年生,副研究员. 
有短时间尺度的场次模型,也有长时间尺度的连续模型; 既有基于水力学基础的模型 ${ }^{[6]}$,也有基于水文学 基础的模型 ${ }^{[7]}$, 等等. 不同的模型具有不同的计算精度及使用范围. 近十多年来,随着 GIS 技术、水文水力学 模拟技术以及营养盐输移理论的不断进步与发展, 模型研究有了长足的进步 ${ }^{[5-13]}$. 但是, 许多研究 (特别是 国内在该方面的研究) 普遍存在如下不足:(1) 没有对营养盐的发生、营养盐从流域向河流系统排放以及河 流系统的营养盐输移等三个主要过程进行详细剖析, 因而, 在研究中仅仅关注其中的某个过程或某两个过 程, 而对于其它过程进行简化处理. 例如,在国内的研究中, 普遍没有对农业土地的营养盐剩余量(或发生 量) 开展研究, 因而, 营养盐排放量的计算结果具有很大的不确定性; (2)轻视基础数据的收集与处理. 与营 养盐排放量计算的基础数据 (包括 GIS 数据) 往往有很多,如流域数字地形模型 (DEM)、土地利用图、土壤 类型图、水文水质监测数据以及点源空间信息等,这些数据的丰富程度及可靠性对研究结果的影响非常大; (3) 在使用他人开发的模型进行计算时,缺少模型参数率定及模型验证,计算结果的可靠性得不到保证等 等. 因此,在营养盐排放量研究方面还有许多工作需要开展.

本研究选择太湖西南部的河流流域——西筥溪流域为典型研究区域,在充分收集大量原始资料的基础 上, 参照 MONERIS 模型系统的结构 ${ }^{[13]}$, 建立流域农业土地的营养盐剩余模型、营养盐排放模型以及河流的 营养盐滞留与损失模型,对流域 $1992-1996$ 年及 $1997-2001$ 年间的营养盐排放量进行计算.

\section{1 材料与方法}

\section{1 研究框架}

流域营养盐从产生到进人河流系统需要经历一系列 的由水和泥沙参与的复杂的运移过程. 在充分获取这些 过程的若干知识的基础上,环境科学工作者构建了一系 列概念性的营养盐排放模型 (或模型系统). 目前, 在欧洲 广泛使用的 MONERIS 模型就是一个代表. 该模型是一个 以流域营养盐排放为核心的分散结构模型, 模型计算主 要以年为单位. 模型共考虑 7 个分散排放途径, 其中 4 个 为面源的分散途径, 其余 3 个分别是大气沉降、城市系统 及点源的排放途径. 模型中的水文计算采用的是径流系 数法,径流组分的计算利用经验公式法.

本项研究首先对 MONERIS 的排放模型在中国南方 地区的适用性开展研究, 然后对模型进行改进. 改进后的 MONERIS 排放模型有 6 个营养盐排出途径 (图 1). 通过 采用我国新安江模型 ${ }^{[14]}$ 的径流量计算结果, 建立适合于 太湖区域特点的营养盐排放模型. 将营养盐排放模型与 营养盐平衡模型以及营养盐的滞留与损失模型, 形成模 型系统.

技术流程是: 首先通过构建农业土地的营养盐平衡

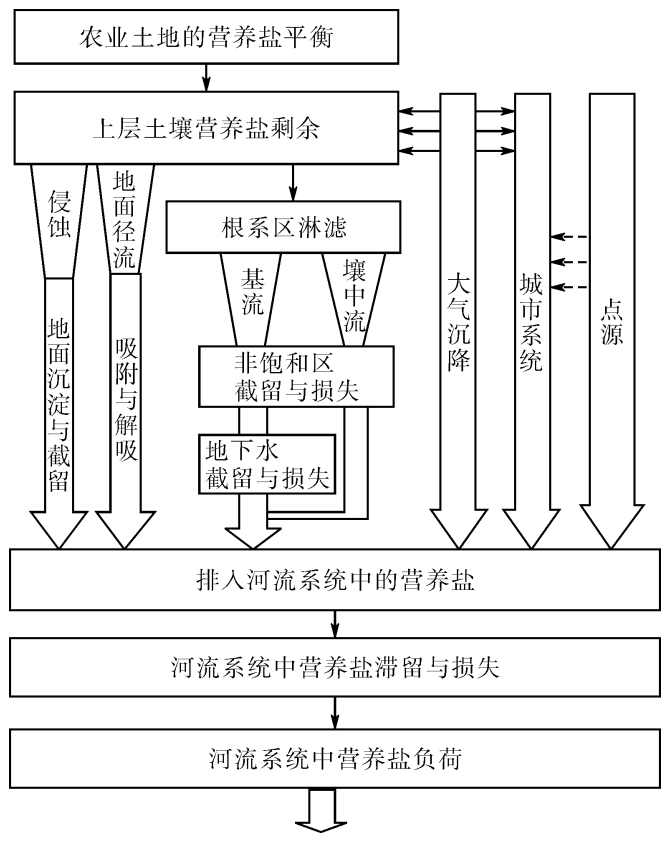

图 1 营养盐排放途径

Fig. 1 Pathways of nutrient emissions 模型,计算土地或上层土壤的营养盐剩余量, 然后, 通过构建与新安江模型耦合的流域营养盐排放模型, 计 算出通过土壤侵蚀、地面径流、地下径流 (壤中流 + 基流)、大气沉降、城市系统以及点源等 6 个分散排放途 径排人到河流系统的营养盐数量, 在此基础上, 建立河流系统的营养盐滞留与损失模型, 将营养盐排放量转 换为负荷量, 并与实测负荷进行对比. 如比对结果合理, 就认为排放量的计算结果是正确的.

\section{2 流域数据库及子流域划分}

研究区域西管溪流域位于太湖南部,流域面积 $3650 \mathrm{~km}^{2}$, 其中山丘区面积占 $65 \%$. 流域人口 134 万人, 其中农业人口 91 万人 (2001 年). 流域平均高程 $114 \mathrm{~m}$, 平均坡度为 $11 \%$. 流域农业土地(含牧草地) 面积占 $42 \%$,林业土地面积占 $52 \%$,其它土地 (城镇、水面、湿地及开阔地) 面积占 $6 \%$.

GIS 数据库的构建是流域营养盐剩余、排放及负荷等研究的基础工作. 项目的研究目的是揭示人类活 
动对流域营养盐排放的影响. 因此, 项目所确定的目标是, 不仅需要得到时间尺度上的营养盐的排放量变 化,而且需要获取到小分辨率的空间尺度上的营养盐的排放量变化. 为此,本项目以庞大的 GIS 数据库作为 研究支撑,数据库的内容包括:(1)包括等高线、高程点、河流、湖泊、水库、鱼塘及居住地等矢量信息在内的高 精度基础地理数据库 (从 147 张 1: 10000 地形图中提取); 2包括降水、蒸发、流量、水位、湿度、风速等资料 在内的水文气象数据库; (3)水和大气环境监测数据库; (4)污水处理厂及工业点源的营养盐排放数据库; (5)以 乡镇为单元的长系列社会经济数据库; (6)土壤流失数据库; (7)土地利用/覆被数据库 ( 提取自高分辨率卫星 影像); (8)土壤数据库; (9)水文地质数据库; (10城市排水管网数据库;等等. 数据库数据信息量达 100 万个 以上.

利用数据库中的等高线及高程点信息,构建 $10 \mathrm{~m} \times 10 \mathrm{~m}$ 高分辨率的 DEM. 利用 Arcview 软件的水文分 析模块, 自动实现流域水系提取、子流域划分及拓扑关系建立. 通过对照 1:10000 图的水系, 经对 DEM 处 理, 提取到合乎需要的水系及子流域. 最终提取的子流域个数为 133 个. 子流域的最大面积为 $112.65 \mathrm{~km}^{2}$, 最小面积为 $0.13 \mathrm{~km}^{2}$, 平均面积为 $27.44 \mathrm{~km}^{2}$. 并在此基础上, 提取出流域营养盐排放模型所需的各子流域 的水文参数及地形参数.

\section{3 模型系统}

1.3.1 农业土地的营养盐剩余模型 农业土地的营养盐剩余量的计算是农业面源营养盐排放量计算的基 础. 通过构建区域农业土地的营养盐平衡(剩余) 模型, 在收集乡镇的长系列的农业资料的基础上,计算营 养盐剩余量的长期变化. 模型的构建方法参考有关文献 ${ }^{[15-17]}$.

1.3 .2 流域营养盐排放模型 流域营养盐排放是一种分散排放过程. 每一种分散途径,形成一种排放量. 将 各种排放量相加,得到流域 (子流域) 的总的排放量. 大部分流域营养盐排放模型皆是根据排放途径的不同 而建立起来的. 在 MONERIS 模型中, 共考虑 7 种分散途径. 根据研究区域的特点, 本项研究减少了一个途 径. 减少后的分散途径有:土壤侵蚀、地面径流、地下径流 (壤中流 + 基流)、大气沉降、城市系统以及点源. 根据这 6 个途径,建立 6 个计算模块. MONERIS 模型的水文计算比较简单,年径流量的计算采用的是径流 系数法,径流组分的计算利用经验公式法. 通过与实测资料对比,发现水文计算的误差较大. 因此,本研究采 用新安江模型的径流量计算结果替代原来结果. 各模块计算方法的详细论述参见相关文献 ${ }^{[11]}$. 下面是各模 块的简单陈述:

(1) 土壤侵蚀的营养盐排放量主要依据土壤的营养盐含量、土壤侵蚀率、泥沙的营养盐富集率及泥沙 搬运率等因素进行确定. 土壤的营养盐含量依照土壤图及营养盐的长期剩余和累积进行计算; 土壤侵蚀率 可直接利用农业部门公布的各流域的侵蚀模数,也可基于通用土壤侵蚀方程(USLE)进行计算;泥沙的营养 盐富集率利用大水流时实测的 SS 的营养盐含量以及估算的土壤营养盐含量进行确定; 泥沙搬运率依据 DEM 及土地覆被图进行计算.

(2)农业地表径流营养盐的排放量与地表径流量及径流的营养盐含量有关. 营养盐含量根据土地利 用、大气沉降率以及土壤中的营养盐剩余与累积水平等因素进行确定.

(3) 地下水的营养盐排放量为地下水流量与地下水营养盐浓度之积. 地下水营养盐浓度与农业土地的 营养盐剩余水平、土壤属性及水文地质特性等因素有关. 农业土地的营养盐剩余水平决定了根系区渗漏水 的营养盐含量, 土壤属性及水文地质属性是确定营养盐滞蓄与损失的必要条件.

(4) 通过大气沉降直接降人到河流系统的营养盐量与流域面积、大气沉降率及流域水面率有关. 将三 者相乘, 就得到计算结果.

(5) 城市系统排放的营养盐与城市人口,城市用地结构,城市不透水面积,下水道的类型与特性, 不同 类型下水道所连接的人口数量,城市污水厂处理规模及处理效果, 以及城市所在区域的暴雨频率及暴雨量, 等若干因素有关. 在详细收集以上资料的基础上,构建城市系统的营养盐排放模型,计算出系统的营养盐输 出量.

(6) 点源排放的营养盐与污水排放量及营养盐的排放浓度有关. 与点源排放相关的数据清单有:点源 空间位置信息, 企业类型, 污水排放量, 污水处理情况及处理效果, 尾水排放浓度等. 对于缺乏污水数据的企 业, 通过与同类企业工业产值的比较, 确定排放量. 
1.3 .3 河流系统的营养盐滞蓄及损失模型 某一时间内河流系统的年平均输运量或营养盐负荷是点源 $\left(E_{\text {point }}\right)$ 及分散源 $\left(E_{\text {diffuse }}\right)$ 的排放总量 $\left(E_{N, P}\right)$ 减去河道滞留及损失总量 $\left(R_{N, P}\right)$ :

$$
L_{N, P}=E_{N, P}-\sum E_{\text {point } N, P}+\sum E_{\text {diffuse } N, P}-\sum R_{N, P}
$$

假如负荷量及点源和面源的排放量是已知的, 那么根据上述公式就可以估算出营养盐的滞留或损失量. 由 于流域的大小不同, 因此在对流域进行比较时,消除流域面积的影响显得非常重要. 定义 $R_{L_{N, P}}$ 是滞留与损 失总量占输运量的权重 $\left(R_{N, P}\right.$ 除以 $\left.L_{N, P}\right)$, 那么, 上述方程可以表示为:

$$
R_{L_{N, P}}=\frac{E_{N, P}}{L_{N, P}}-1=\frac{1}{L_{E_{N, P}}}-1
$$

该方程揭示了滞留与损失总量占负荷量的权重 $\left(R_{L_{N, P}}\right)$ 与负荷量占排放量的权重 $\left(L_{E_{N, P}}\right)$ 之间的关系. 因此,利用 $L_{E_{N, P}}$ 对数据进行标准化处理, 就可以使流域面积的影响得到消除.

借鉴湖泊的脱氮损失的物质平衡模型 ${ }^{[18]}$, 河流系统的营养盐滞留与损失权重 $\left(R_{L_{N, P}}\right)$ 可以用下面的模 型进行描述 ${ }^{[19]}$ :

$$
R_{L_{N, P}}=a \cdot x^{b}
$$

式中, $x$ 是驱动力, $a, b$ 是模型系数. 驱动力用单位面积径流量或水力负荷表示. 水力负荷表示的是单位时间 内流过河流系统每平方公里水面的平均水面高度. 因此, 年平均水力负荷 $(H L)$ 的计算公式如下:

$$
H L=\frac{q \cdot 8.64 \cdot 0.365}{W}
$$

式中, $q$ 是单位面积径流量 $\left(\mathrm{L} /\left(\mathrm{km}^{2} \cdot \mathrm{s}\right)\right), W$ 是水面率 $(\%)$.

\section{2 计算结果}

\section{1 模型系统的调试及参数选取}

模型 (系统) 计算结果与实测数据的符合程度, 是检验模型 (系统) 是否正确的唯一手段. 模型调试及参 数选取是建立水文及环境模型的一个基本步骤. 本项研究首先利用 5 个年份的水文资料,对新安江模型进 行集总调试,并获取模型参数. 然后,对各年份各子流域的径流量及径流组分进行计算. 将计算出的各子流 域的径流数据代人改进的 MONERIS 模型, 计算出各子流域营养盐排放量的初值. 然后, 利用河道滞留模型, 计算出不同河流断面的营养盐负荷量. 通过与实测的负荷量对比, 对改进的 MONERIS 模型中的敏感参数 进行调整 ${ }^{1}$, 重新计算排放量, 直至验证结果令人满意. 最后计算得到的 133 个子流域的营养盐排放量即为 最终的排放量成果.

验证结果表明, 所有监测点 TN、TP 及 DIN 的计算负荷与实测负荷的平均偏差均在 30\% 以下 (图 2), 其 中 $\mathrm{N}$ 的平均偏差仅为 $9.2 \%$. 偏差比较大的点主要与点源的空间信息不准有关.

\section{2 计算结果}

2.2 .1 氮 在 $1997-2001$ 年期间,平均每年有 $5645.5 \mathrm{t}$ 进人太湖南部的河流系统 (表 1). 与 $1992-1996$ 年 相比,氮的排放量减少 $12.8 \%$. 从不同排放途径来看, 地下水排放的氮量最多, 占总排放量 $50 \%$ 以上, 工业 点源及污水处理厂排放的氮量排第二位,占 $20 \%$ 左右,城市系统排放的氮量排第三位,占 $10 \%$ 左右. 通过其 它途径排放的氮量相对较少. 从面源排放及点源排放的构成来看,面源约占 $2 / 3$, 点源约占 $1 / 3$ (面源取表 1 前 4 项,点源取后 2 项).

从 133 个子流域的单位面积氮排放量的空间变化来看, 不同时期的空间差异均十分显著. 以 $1997-$ 2001 年期间的氮排放量为例, 最大、最小值分别为 $52.42 、 0.68 \mathrm{t} /\left(\mathrm{km}^{2} \cdot \mathrm{a}\right)$, 相差 77 倍. 与全流域的均值相 比, 最大值大 34 倍, 最小值小 3 倍. 从总体上看,包含城镇及工业区的子流域的排放量大于不含城镇及工业 区的子流域的排放量,农业面积权重大的子流域的排放量大于权重小的子流域的排放量, 下游子流域的排 放量大于上游子流域排放量. 
表 1 太湖西南部河流流域的营养盐的不同排放途径的排放量

Fig. 1 Nutrient emissions into the river systems of the southwestern Taihu Basin

\begin{tabular}{|c|c|c|c|c|c|c|c|c|}
\hline \multirow{2}{*}{ 排放途径 } & \multicolumn{4}{|c|}{$1992-1996$ 年 } & \multicolumn{4}{|c|}{$1997-2001$ 年 } \\
\hline & $N(t / a)$ & 比例 (\%) & $P(t / a)$ & 比例 (\%) & $\mathrm{N}(\mathrm{t} / \mathrm{a})$ & 比例 (\%) & $P(t / a)$ & 比例 (\%) \\
\hline 大气沉降(水面) & 39.7 & 0.6 & 3.0 & 0.5 & 51.8 & 0.9 & 3.0 & 0.5 \\
\hline 壤中流及基流 & 3658.4 & 56.5 & 43.0 & 7.2 & 2938.9 & 52.1 & 42.4 & 7.7 \\
\hline 地面径流 & 316.2 & 4.9 & 103.3 & 17.3 & 374.7 & 6.6 & 101.8 & 18.4 \\
\hline 侵蚀 & 414.9 & 6.4 & 133.6 & 22.3 & 361.6 & 6.4 & 136.0 & 24.5 \\
\hline 点源及污水处理厂 & 1504.5 & 23.2 & 217.7 & 36.4 & 1253.8 & 22.2 & 181.4 & 32.7 \\
\hline 城市系统 (总) & 538.8 & 8.3 & 97.9 & 16.4 & 664.6 & 11.8 & 89.6 & 16.2 \\
\hline 总排放量 & 6472.6 & 100.0 & 598.5 & 100.0 & 5645.5 & 100.0 & 554.2 & 100.0 \\
\hline
\end{tabular}
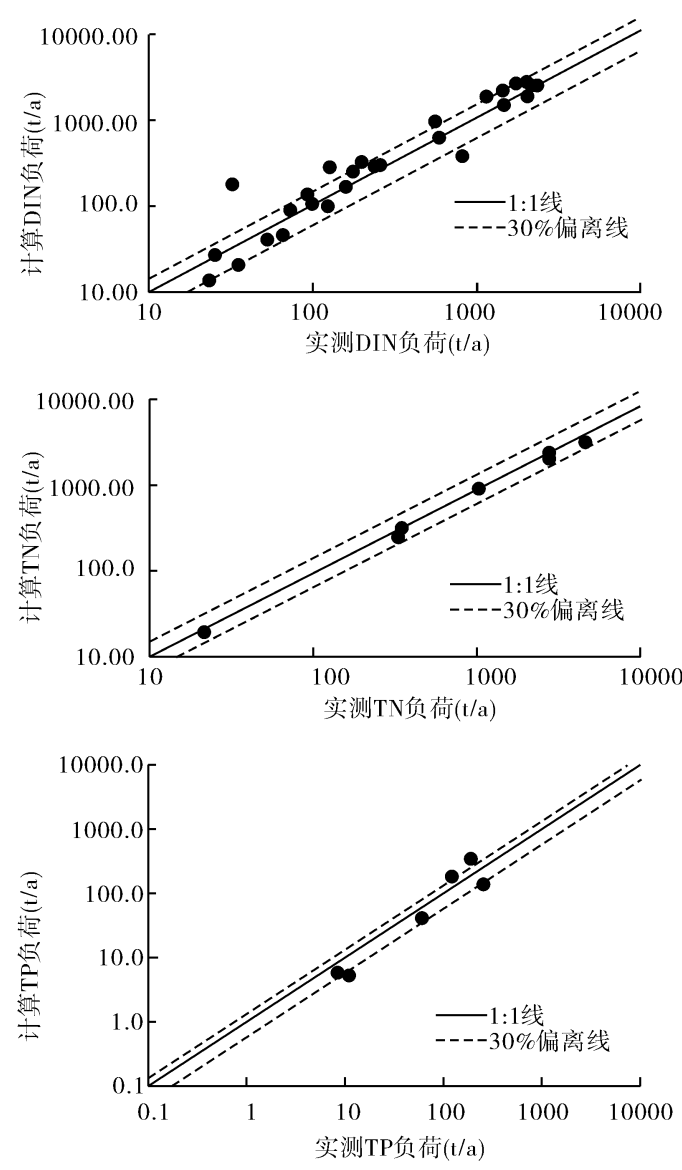

图 2 DIN, TN 及 TP 的实测负荷与计算负荷比较

Fig. 2 Comparison of measured and calculated loads of DIN, TN and TP(1997-2001)
2.2 .2 磷 $1992-1996$ 年及 $1997-2001$ 年磷的排放量 分别为 $598.5 \mathrm{t} / \mathrm{a} 、 554.2 \mathrm{t} / \mathrm{a}$ (表 1 ), 后五年的排放量比 前五年减少 $7.4 \%$. 从点源及污水处理厂进入河流系统 的磷量最多,约占总人河量的 $1 / 3$, 从侵蚀泥沙输运到河 流系统的磷量排第二位, 约占 $1 / 4$, 从城市系统或地面径 流进人河流系统的磷量占 $1 / 6-1 / 5$. 通过其它途径排放 的磷量相对较少. 从面源排放及点源排放的构成来看, 各约占一半.

与氮的排放量一样,不同时期各子流域的单位面积 磷排放量的空间差异也十分显著. 在 $1997-2001$ 年期 间, 磷排放量的最大、最小值分别为 $3.71 、 0.03 \mathrm{t} /\left(\mathrm{km}^{2}\right.$. a), 相差 124 倍. 与全流域的均值相比, 最大值大 23 倍, 最小值小 5 倍.

\section{3 分析与讨论}

流域营养盐的输人及输出涉及到自然与社会的方 方面面, 因此,需要通过大量的工作,才能构建出具有物 理基础的复杂的模型系统. 充分了解营养盐的产生方式 及运移过程, 是进行模型的概念设计及系统设计的基础 工作. 借鉴其它模型的设计理念, 采用剩余 $\rightarrow$ 排放 $\rightarrow$ 河 流滞蓄一河流系统负荷的概念途径, 能够真实反映营养 盐从输人到输出的整个过程.

通过面源排放的营养盐主要与农业土地中营养盐 的剩余量有关. 营养盐剩余量的估算精度与化学肥料的 统计精度、畜禽排放系数的取值以及农作物输出系数的 取值等因素有关,相关文献已经作了充分阐述 ${ }^{[17]}$.

在营养盐排放模型中,归纳了营养盐的 6 个分散排 放途径. 这些途径全面地反映了营养盐从大气、企业、污 水处理厂、城市系统、径流以及侵蚀等途径进人河流系 统的排放方式. 在不同分散途径之间, 营养盐不同形式的转换、损失及滞留已经加以区别对待. 从模型应用 来看,模型的描述是合理的.

大气氮沉降采用流域平均的 $\mathrm{NO}_{\mathrm{x}}-\mathrm{N}$ 及 $\mathrm{NH}_{4}-\mathrm{N}$ 沉降量 $\left(\mathrm{kg} /\left(\mathrm{hm}^{2} \cdot \mathrm{a}\right)\right)$. 考虑到流域内三个大气测点均 
位于市区, 其平均沉降量不具有代表性. 流域平均沉降量还需乘以一个折算系数, 取 0.8 . 磷的沉降率采用 统一值 $0.3 \mathrm{~kg} /\left(\mathrm{hm}^{2} \cdot \mathrm{a}\right)$. 根据土地利用图, 沉降到水面的营养盐为直接排放量, 沉降到其它土地类型的营 养盐参与到相关的流域过程计算. 与其它排放量相比, 大气沉降的排放量相对较小 (仅 $1 \%$ 左右), 因而, 其 计算误差对系统的整体误差不会构成较大影响.

部分点源排放的营养盐数据是环境部门的推算结果. 这一结果可能与实际情况存在差异. 据环境部门 估计,误差范围可能在 10\%-30\% 之间. 受此影响,系统的整体误差可能达 3\%-8\%.

城市的营养盐排出途径可以被归纳为: (1)通过下水道系统 一城市污水处理厂的排放; (2)通过没与污水 处理厂连接的下水道系统的排放; (3)不透水区的面状排放 (指没有与下水道系统连接的区域) ; (4)下水道系 统的暴雨径流溢出 (指与污水处理厂连接的合流系统). 由于缺少城市区的微地形资料及人口密度的空间 分布资料, 本研究作了如下假定: (1)各区域人口密度相等; (2)城市地势平坦, 流向各方向的流量相等; (3)下水 道系统连接了所有的不透水面. 在此基础上, 根据城市的排水管网图, 计算每种下水道系统所连接的人口数 量及不透水区面积. 城市居民营养盐排放的人口当量: 氮为 $10 \mathrm{~g} / \mathrm{d}$, 磷为 $1.6 \mathrm{~g} / \mathrm{d}$. 单位不透水面积的氮排放 量为大气氮沉降量及落叶和动物粪便之和 $\left(4 \mathrm{~kg} /\left(\mathrm{hm}^{2} \cdot \mathrm{a}\right)\right)$, 磷排放量是 $2.5 \mathrm{~kg} /\left(\mathrm{hm}^{2} \cdot \mathrm{a}\right)^{[19]}$. 城市土壤的 N、P 滞留系数均取 70\%. 由于安吉、长兴两城市的污水处理厂直至 2001 年以后才运行, 因此这两个城市的 营养盐排放量即为营养盐产生量扣除系统滞留量以后的量值. 城市系统的排放量计算误差与各系数的取值 有关, 取国外使用过的各系数的最高、最低值进行计算, 最大偏差可达 $15 \%$. 按城市 N、P 排放量占流域总排 放量的 $10 \%$ 及 $20 \%$ 计算,城市系统的估算误差对总排放量的误差的贡献率应为 $2 \%-3 \%$.

通过侵蚀排放的营养盐的计算误差与多种因素有关, 其中, 土壤的营养盐含量及土壤侵蚀率的计算结 果对误差影响较大. 由于土壤的磷的累积量已经通过长系列的营养盐剩余模型计算出来, 因此, 排放量的误 差主要与土壤侵蚀率的计算结果有关. 本研究采用两种方法确定各子流域的土壤侵蚀率: 一是以农业部门 公布的各主要流域的侵蚀模数为基础, 通过比较子流域与主要流域的坡度及耕地比例的差异, 确定子流域 的侵蚀模数, 二是基于通用土壤侵蚀方程 (USLE) 进行计算. 利用水文站的多年平均的输沙量资料, 对结果 进行比较. 结果发现, 前一种简单方法的计算误差并不是很大 ( $4.2 \%)$. 因此, 在进行营养盐排放计算时, 直 接采用前一方法的侵蚀率计算结果. 流域系统总排放量的计算结果受此影响不大.

地表径流排放的是溶解态的营养盐. 采用的计算方法是面积 - 权重法. 由于农业土壤中长期的 P 剩余 水平对上层土壤中颗粒态及溶解态 $\mathrm{P}$ 起决定性作用, 因此, 一般认为地表径流中 $\mathrm{P}$ 浓度与土地利用有关. 庄 稼地的溶解态 $\mathrm{P}$ 的浓度最高, 草地中等, 非农业区最低. 对于地表径流中 $\mathrm{N}$, 除来源于大气沉降外, 还与土壤 的贡献有关 (仅对庄稼地而言). 许多研究认为 ${ }^{[20]}$, 只要获得农业土地的长系列的营养盐剩余资料以及土壤 中磷的累积量,地表径流的营养盐排放量的计算结果就比较可靠.

许多研究表明, 在土壤发育良好的湿润流域, 地下水 (壤中流及基流) 的氮排放量较多. 本项研究也支 持这一结论. 地下水有好氧及厌氧之分, 在厌氧地下水中, 特别是深层的厌氧地下水, DIP 及 TP 浓度差别很 大. 由于这一原因, TP 浓度通常比 SRP 高 2-5 倍. 目前, 人们还难以取得厌氧的地下水的面积. 不过, 人们 可以利用厌氧条件的概率高低来确定, 这个概率通过比较地下水与渗透水的 $\mathrm{N}$ 浓度进行确定 ${ }^{[20]}$. 对于地下 水的 $\mathrm{TP}$ 浓度, 采用如下假定 ${ }^{[20]}$ : 假如地下水中 $\mathrm{N}$ 浓度比渗透水中 $\mathrm{N}$ 浓度低 $15 \%$, 那么, 地下水中 $\mathrm{TP}$ 浓度 是 SRP 浓度的 2.5 倍. 利用以上信息及其它相关信息, 计算各子流域 TP 浓度, 计算结果为 $0.007-0.03 \mathrm{mg} /$ $\mathrm{L}$ 之间. 这个结果与承压水井中水样的化验结果比较一致. 地下水中 $\mathrm{N}$ 来源于渗漏水中的硝酸盐氮. 要得到 这个数据, 必须首先获取从根系区到地下水以及地下水本身的水的滞留时间. 到目前为止, 还难以取得不饱 和区及地下水含水层滞留时间的详细模型结果. 参考有关文献 ${ }^{[20]}$, 在计算 $\mathrm{N}$ 剩余系列的滑动平均值的基础 上, 与河流的硝酸盐浓度观测值的长期变化进行比较, 估算出滞留时间. 根据估算结果, 对不同流域的 $\mathrm{N}$ 剩 余进行纠正, 然后, 计算出渗漏水中的硝酸盐浓度, 以及 $\mathrm{N}$ 滞留量及非饱和区向饱和区的转换量. 通过与国 外的相似流域的研究成果比较, 地下水排放量计算结果的高估或低估的可能性不大.

综上所述, 流域系统营养盐总排放量的低估或高估值应该不会很高.

湖泊的营养盐滞留损失是一个公开的问题, 自从 Vollenweider 开展研究以来 ${ }^{[21]}$, 湖泊的损失已经被人 们接受, 并认为该损失是可以预测的. 早期的流域营养盐排放研究主要针对小流域而言,并且在多数情况下 
假定在如此小的流域内水体之内的营养盐运动过程可以被忽略. 因此, 河流系统的营养盐滞留及损失不为 人们所认识. 随着研究的逐步深人, 人们也渐渐认识到, 河流系统 (特别是大的系统) 的营养盐损失是存在 的. 就象许多研究者所指出的那样 ${ }^{[20,22]}$, 忽略河流系统滞留过程的假定是完全错误的. 甚至有研究者认为, 河流及湖泊脱氮过程的强度是一样的. 与湖泊一样, 在储蓄水量相同的情况下,水深浅、湿周长、沉积物面积 大的河流往往具有较高的脱氮率. 另外, 底栖生物 (如沉水及浮叶植物及贝壳类动物) 对营养盐的进一步消 耗使营养盐的损失量更大 ${ }^{[23,24]}$.

随着对点源及分散源营养盐排放途径方面知识的不断增加,应用不同估算方法得到的流域营养盐排放 量的标准偏差得到有效降低 ${ }^{[19]}$. 系统高估或低估的可能性已经降至最低. 尽管如此, 人们还是发现, 营养盐 排放量与河流系统输运量之间存在较大差异. 通过统计不同作者发表的较为可靠的 62 个流域的营养盐排 放量估算数据(这些流域多位于中欧), 经与负荷量比较发现,前者比后者平均高约 $60 \%$. 造成这一现象的 原因, 可能是高估或低估了营养盐的排放量及负荷量 (输运量), 也可能是河流系统存在着营养盐的滞留和 损失. 由于河流的营养盐监测数据一般是非连续的数据, 因此,根据年内的有限次数的浓度数据来计算负荷 量, 一定存在误差. 目前, 在中国及中欧等国, 水质的监测频次多为每年 6 次. 根据环太湖人湖河流 $2001-$ 2002 水文年的水质监测数据 (1)分析, 如年内的监测频率从 15 次降为 6 次 (丰、平、枯各两次), 那么, 营养盐 的年均浓度将出现 10\%-20\% 的平均偏差 ( DIN 为 $14 \%$ 、TN 为 $11 \%$ 及 TP 为 $17 \%$ ). 如果该数值即是代表 的各种负荷量的计算偏差值, 同时假定营养盐排放量的计算偏差为 $10 \%-20 \%$,那么不同流域的平均的滞 留及损失率至少应有 $20 \%$ (排放量计算偏差取 $-20 \%$, 即低估 $20 \%$, 负荷量计算偏差取 $+20 \%$, 即高估 $20 \%$ ). 本研究计算得到的营养盐排放量均显著高于实测的负荷量, 特别是 $\mathrm{P}$, 高达 $50 \%$ 以上, 因此, 本研究 充分证明了营养盐的滞留与损失的存在.

众所周知, 自然界的氮的化合物也存在着反硝化作用,这种作用使得氮能够脱离它所依赖的介质. 因 此, 在一个短的时间尺度内, 氮的损失是存在的. 但是, 对于一个长的时间尺度而言,氮的损失是否存在或是 否具有显著性,还要看与氮有关的其它过程的强弱程度 (如氮的硝化、生物分解等). 在营养盐的动力学研 究中, 尽管人们已经考虑了营养盐的物理、化学及生物作用,并且在河流的某些地方能够直接测量与水质模 型有关的沉降系数、降解系数及底泥释放系数 ${ }^{[22]}$, 并被用来计算滞留、损失及释放过程. 但是, 要将测量结 果向上递推(扩大)到一个完整年份或整个流域的河流系统,往往比较困难.

随着流域营养盐的剩余、排放及负荷研究的逐步深人, 人们也逐渐揭示了河流系统的营养盐的滞留与 损失, 并且构建了如 Vollenweider 类型模型的概念模型. 从相关模型的方法出发 ${ }^{[19]}$, 本研究建立的滞留模型 也具有较高的可信度, 研究结果较好 (图 1). 对于 TN 及 DIN 来讲, 与水力负荷的关系较密切 (1997-2001 年期间 $H L$ 为 $37 \mathrm{~m} / \mathrm{a}$ ), 因此, 水力负荷是驱动力, $\mathrm{TN}$ 滞留模型的 $a 、 b$ 系数取 $2.88 、-0.49$, DIN 滞留模型的 $a 、 b$ 系数取 $12.9 、-0.91$. TP 与单位面积径流量的关系较密切, 因此单位面积径流量是驱动力, TP 滞留模型 的 $a 、 b$ 系数取 $24.5 、-1.65$. 由于实测 $\mathrm{TN} 、 \mathrm{TP}$ 的数据还很少, 因此, 模型的系数取值是暂时的.

\section{4 参考文献}

[1] 金相灿等. 中国湖泊富营养化控制与管理技术. 北京: 化学工业出版社, 2001.

[2] Tappin A D. An examination of the fluxes of nitrogen and phosphorus in temperate and tropical estuaries: current estimates and uncertainties. Estuarine, Coastal and Shelf Science, 2002, 55: 885 - 901.

[3] 杨桂山等. 流域综合管理导论. 北京: 科学出版社, 2004: 157-161.

[4] 李恒鹏, 杨桂山, 黄文钰等. 不同尺度流域地表径流氮、磷浓度比较. 湖泊科学, 2006, 18(4): 377 -386 .

[5] Ryding S O and Rast W. 朱 萱等译. 湖泊与水库富营养化控制. 北京: 中国环境科学出版社, 1992.

[6] Martin J L, McCutcheon S C. Hydrodynamics and Transport for Water Quality Modeling. Lewis Publishers, CRC Press Inc, 1999.

(1) 许朋柱等, 《环太湖河道的水量及污染物通量数据集》,2003. 
[7] Santhi C, Arnold J G, Williams et al. Validation of the SWAT model on a large river basin with point and nonpoint sources. Journal of American Water Resources Association, 2001, 37: 1169 - 1188.

[8] Cooper D M, Naden P S. Approaches to delivery modelling in LOIS. Sci Tot Envir, 1998, 210: 483 - 498.

[9] Wit M, Bendoricchio G. Nutrient fluxes in the Po basin. Sci Tot Envir, 2001, 273: 147 - 161.

[10] Zessner M, van Gils J. Nutrient fluxes from the Danube basin to the Black Sea. Wat Sci Tech, 1999,46 (8) : $9-17$.

[11] Behrendt H, Dannowski R ed. Nutrients and Heavy Metals in the Odra River Systems. Berlin: Wei ensee Verlag, 2005.

[12] Behrendt H, Bachor A. Point and diffuse load of nutrients to the Baltic Sea by river basins of North East Germany (Mecklenburg-Vorpommern). Wat Sci Tech, 1998, 38 (10) : 147 - 155.

[13] Behrendt H, Kornmilch M, Opitz D et al. Estimation of the nutrient inputs into river systems - experiences from German rivers. Regional Environmental Changes, 2002, 3: 107 - 117.

[14] 赵人俊. 流域水文模拟一一新安江模型及陕北模型. 北京: 水利水电出版社, 1982 .

[15] OECD. OECD National Soil Surface Nutrient Balances: 1985 To 1996, Explanatory Notes. Paris: OECD Secretary, 1997.

[16] Somloydy L, Brunner P H, Kroiß H. Nutrient balances for Danube countries: a strategic analysis. Wat Sci Tech, 1999,40 (10): 9-16.

[17] 许朋柱, 秦伯强, Behrendt H 等. 太湖上游流域农业土地的氮剩余及其对湖泊富营养化的影响. 湖泊 科学, 2006, 18(4) : $395-400$.

[18] Kelly C A, Rudd J W M, Hesslein R H et al. Prediction of biological acid neutralization in acid sensitive lakes. Biogeochemistry, 1987, 3: $129-141$.

[19] Behrendt H, Opitz D. Retention of nutrients in river systems: dependence on specific runoff and hydraulic load. Hydrobiologia, 2000, 410:111 - 122 .

[20] Behrendt H. Inventories of point and diffuse sources and estimated nutrient loads a comparison for different river basins in Central Europe. Wat Sci Tech, 1996, 33: 99 - 107.

[21] Vollenweider R A. The scientific basis of lake and stream eutrophication, with particular reference to phosphorus and nitrogen as eutrophication factors. Paris: Tech Rep, OECD, DAS/CSI/68, 27 : 1 - 182.

[22] Billen G J. The PHISON river system: A conceptual model of C, N and P transformations in the aquatic continuum from land to sea. In: Wollast R, Mackenzie F T, Chou L eds. Interactions of C, N, P and Si biogeochemical cycles and global change. NATO ASI Series 1993, 14: $141-161$.

[23] Svendsen L M, Kronvang B. Retention of nitrogen and phosphorus in a Danish lowland river system: implications for the export from the watershed. Hydrobiologia, 1993, 251: $123-135$.

[24] Alexander R B et al. Effect of stream channel size on the delivery of nitrogen to the Gulf of Mexico. Nature, 2000, 403: $758-761$.

[25] Driescher E, Gelbrecht J. Assessing the diffuse phosphorus input from subsurface to surface waters in the catchment area of the lower River Spree (Germany). Water Sci Tech, 1993, 28:337 - 347.

[26] Arheimer B, Brandt M. Modelling nitrogen transport and retention in the catchments of southern sweden. Ambio, 1998, 27: $471-480$.

[27] Petterson A, Arheimer B, Johansson B. Nitrogen Concentrations Simulated with HBV-N: New Response function and Calibration Strategy. Nordic Hydrology, 2001, 32: 227 - 248.

[28] Venohr M, Behrendt H. Modelling the dependency of riverine nitrogen retention on hydrological conditions and temperature. Proceedings 6th Internat. Conf. on Diffuse Pollution, Amsterdam,2002:573 - 574 . 